07;08;09

\title{
Усиление люминесценции квантовых точек вблизи слоя наночастиц $\mathrm{Ag} / \mathrm{SiO}_{2}$
}

\author{
(C) Л.Б. Матюшкин, А. Перцова, В.А. Мошников
}

Санкт-Петербургский государственный электротехнический университет „ЛЭТИ“, Санкт-Петербург, Россия

E-mail: leva.matyushkin@gmail.com

Поступило в Редакцию 4 декабря 2017 г.

Исследовано влияние монодисперсных наночастиц структуры ядро/оболочка $\mathrm{Ag} / \mathrm{SiO}_{2}$ с диаметром ядра $17 \mathrm{~nm}$ и толщиной диэлектрической оболочки в диапазоне 0-40 nm на фотолюминесценцию квантовых точек $\mathrm{CdSe} / \mathrm{ZnS}$ при возбуждении лазером с длиной волны, соответствующей плазмонному резонансу частиц $\mathrm{Ag} / \mathrm{SiO}_{2}$. Продемонстрировано увеличение интенсивности люминесценции композитной системы до 8.7 раз.

DOI: 10.21883/PJTF.2018.08.45964.17142

Способность металлических наночастиц менять характер распространения электромагнитного поля и увеличивать его амплитуду вблизи поверхности частицы применяется в детекторах на основе гигантского комбинационного рассеяния света [1], в биомедицине [2], начинает использоваться в оптоэлектронике [3] и солнечной энергетике [4]. Особый интерес вызывает эффект увеличения интенсивности люминесценции флуорофоров вблизи металлических частиц - эффект „плазмонного усиления“, наблюдающийся как для органических красителей [5], так и для неорганических частиц [6-8]. В квантовых точках $\mathrm{Si}-\mathrm{Ge}$ продемонстрировано плазмонное усиление люминесценции для случая четырехчастичной излучательной рекомбинации [9]. При этом наибольшее увеличение интенсивности люминесценции обычно наблюдается на некотором оптимальном расстоянии $h_{\text {opt }}$ между металлической частицей и флуорофором: с одной стороны, при увеличении расстояния между двумя частицами снижается вероятность туннелирования возбужденных в излучающей частице носителей заряда в металлическую частицу; с другой - амплитуда поля, возбуждаемого в металлической наночастице 
при локализованном поверхностном плазмонном резонансе, быстро убывает при отдалении от поверхности.

Для задания расстояния между плазмонной системой и квантовым эмиттером традиционно используются системы с прослойкой („спейсером“) из различных материалов, таких как $\mathrm{Al}_{1-x} \mathrm{Ga}_{x} \mathrm{As}[10]$, послойно осажденные органические полиэлектролиты [6] или гибридные органо-неорганические системы, в которых частицы распределены в различных матрицах [11]. В настоящей работе предлагается вместо использования отдельных операций создания плазмонных частиц и спейсера совместить эти функции в одной системе, а расстояние между квантовой точкой (КТ) и сферической металлической наночастицей задавать толщиной диэлектрической оболочки $h_{s}$, создаваемой вокруг частиц серебра одинакового диаметра $d$. В отличие от случая ионносинтезированных наночастиц серебра [11] предлагаемый подход позволяет избежать ситуаций, когда металлические наночастицы вблизи поверхности находятся на различном расстоянии от квантовых точек.

Таким образом, для исследования эффекта плазмонного усиления методами коллоидной химии были синтезированы частицы структуры ядро/оболочка $\mathrm{Ag} / \mathrm{SiO}_{2}$. Монодисперсные ядра частиц были получены в результате коллоидного синтеза по методу [12], а для создания оболочек использовался модифицированный метод Штобера [13]. Для получения различной толщины диэлектрической оболочки $h_{s}$ к спиртовому раствору частиц серебра добавлялось различное количество источника оксида кремния - тетраэтоксисилана [14], который в результате реакции гидролиза и поликонденсации преобразовывался в диоксид кремния.

Синтезированные по указанной методике частицы серебра без диэлектрической оболочки проявляют локализованный поверхностный плазмонный резонанс на длине волны $405 \mathrm{~nm}$ (рис. 1). Диаметр частиц, определенный по положению плазмонного резонанса [15] и подтвержденный данными растровой электронной микроскопии, составил $d=17 \mathrm{~nm}$. При увеличении $h_{s}$ происходит смещение максимума плазмонного резонанса в низкочастотную область, обусловленное изменением диэлектрической проницаемости окружающей среды. Спектральные данные коррелируют с результатами работ по коллоидным наночастицам $\mathrm{Ag} / \mathrm{SiO}_{2}$ [13] и $\mathrm{Au} / \mathrm{SiO}_{2}$ [16], в которых аналогичное смещение также наблюдалось для частиц с оболочками до $40 \mathrm{~nm}$. Расчетные толщины оболочек были соотнесены с измерениями выборочных образцов методом атомно-силовой микроскопии и оказались 


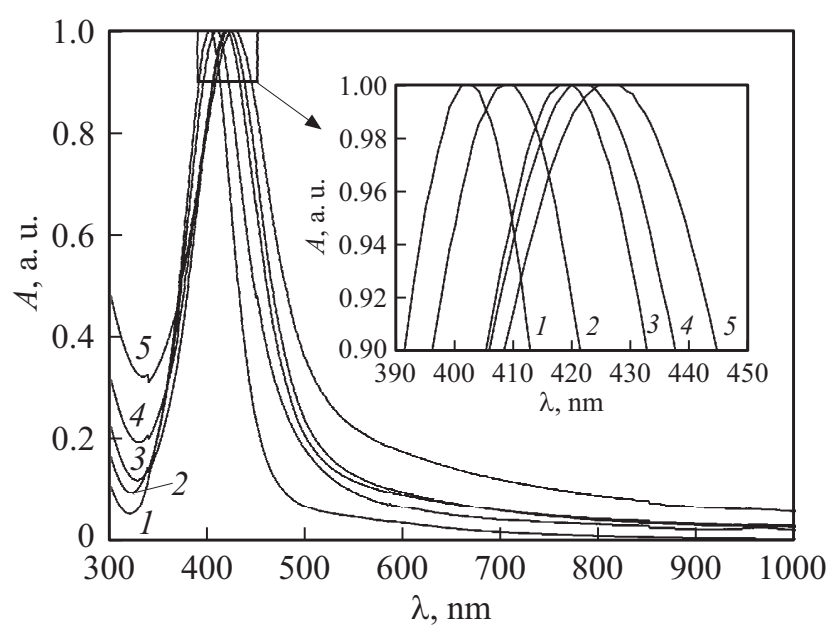

Рис. 1. Спектры оптической плотности наночастиц $\mathrm{Ag}(1)$ и наночастиц $\mathrm{Ag} / \mathrm{SiO}_{2}$ с расчетными значениями толщины $\mathrm{SiO}_{2}$, равными 15 (2), 25 (3), 35 (4), $40 \mathrm{~nm}$ (5). На вставке - увеличенный фрагмент области сдвига максимума.

несколько завышенными. Величина сдвига пика на рис. 1 меньше, чем ожидалось из соответствующего изменения диэлектрического окружения. Причиной этого может являться неполное протекание реакции поликонденсации в золь-гель-процессе, в результате чего происходит образование оболочки меньшей толщины либо образование пористой структуры с отличными от теоретических значениями диэлектрической проницаемости материала оболочки. Здесь и далее для определенности мы указываем расчетные значения толщин оболочки.

Описанные частицы $\mathrm{Ag} / \mathrm{SiO}_{2}$ при помощи центрифугирования были нанесены на кварцевую подложку, после чего поверх этого слоя был нанесен слой из коллоидного раствора промышленных квантовых точек $\mathrm{CdSe} / \mathrm{ZnS}$ (коммерческий образец Sigma Aldrich, диаметр частиц вместе с органической оболочкой октадециламина $4 \mathrm{~nm}$ ) для получения структуры, схематично показанной на рис. 2. Слои KT (QD на рис. 2) наносились при таком соотношении поверхностных концентраций КТ и наночастиц $\mathrm{Ag} / \mathrm{SiO}_{2}$, чтобы можно было пренебречь взаимодействием между КТ и рассматривать преимущественно взаимодействие полупро-

Письма в ЖТФ, 2018, том 44, вып. 8 


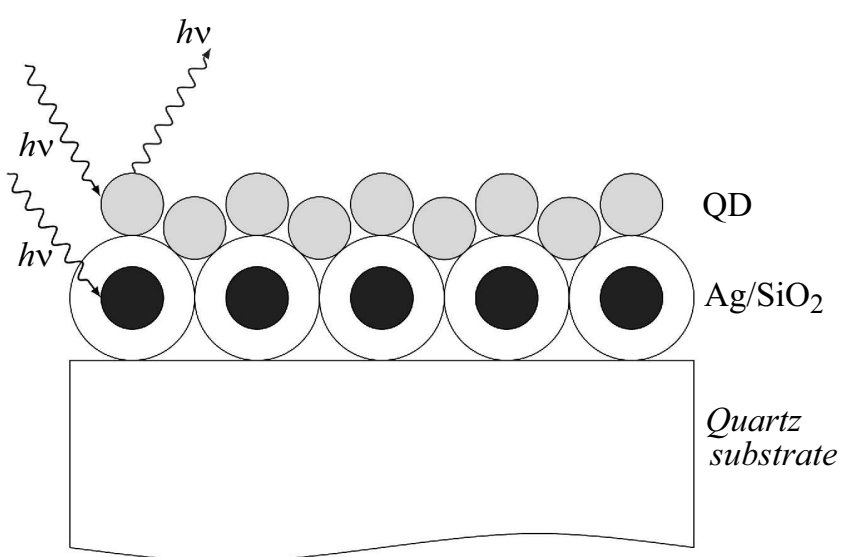

Pис. 2. Схема структуры для исследования плазмонного усиления люминесценции.

водниковых частиц с нижележащим слоем наночастиц $\mathrm{Ag} / \mathrm{SiO}_{2}$. Поскольку размер КТ существенно меньше размера частиц $\mathrm{Ag} / \mathrm{SiO}_{2}$, можно считать, что наиболее вероятно взаимодействие отдельной КТ только с одной плазмонной наночастицей. Возбуждение фотолюминесценции (ФЛ) образца осуществлялось со стороны слоя КТ твердотельным лазером с длиной волны излучения $405 \mathrm{~nm}$.

Для описания эффекта взаимодействия металлических ядер $\mathrm{Ag}$ и квантовых точек CdSe/ZnS введем коэффициент увеличения интенсивности люминесценции $K$

$$
K=\frac{\max \{I(\lambda)\}}{\max \left\{I_{0}(\lambda)\right\}},
$$

где $I(\lambda)$ и $I_{0}(\lambda)$ - спектры ФЛ слоя КТ в присутствии и в отсутствие слоя плазмонных частиц соответственно. Спектры ФЛ структур с плазмонными частицами, нормированные на интенсивность максимума спектра ФЛ структуры без плазмонных частиц, представлены на рис. 3. Можно видеть, что форма спектров и положение максимума не претерпевают существенных изменений при наличии плазмонных частиц. В случае металлических частиц без диэлектрической оболочки не происходит тушения люминесценции, а наблюдается лишь увеличение

Письма в ЖТФ, 2018, том 44, вып. 8 


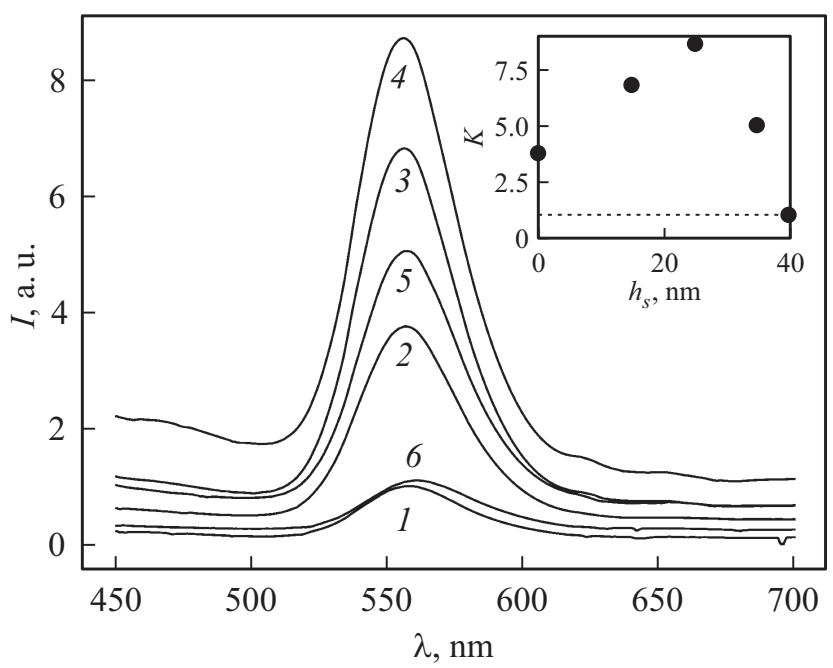

Рис. 3. Спектры фотолюминесценции КТ CdSe/ZnS в отсутствие (1) и вблизи плазмонных частиц с толщиной оболочки $h_{s}=0$ (без оболочки) (2), 15 (3), 25 (4), 35 (5) и $40 \mathrm{~nm}(6)$. На вставке - зависимость коэффициента усиления от толщины оболочки.

интенсивности. Причиной этого может являться наличие в структуре КТ оболочки из широкозонного материала, способствующей локализации носителей заряда. Также заметим, что интенсивность люминесценции растет одновременно с фоновым рассеянием, обусловленным увеличением размера композитных частиц $\mathrm{Ag} / \mathrm{SiO}_{2}$. Это неупругое рассеяние, по всей видимости, является одной из дополнительных причин роста ФЛ.

На вставке к рис. 3 представлена зависимость коэффициента усиления от толщины оболочки. Наибольшее усиление с $K=8.7$ наблюдается при расчетной толщине оболочки $h_{s}=25 \mathrm{~nm}$. Заметим, что при $h_{s}=40 \mathrm{~nm}$ интенсивность ФЛ спадает до исходного уровня. Таким образом, максимум усиления ФЛ наблюдается на некотором оптимальном расстоянии между частицами. Быстрый спад коэффициента усиления при увеличении толщины оболочки обусловлен ближнепольным характером усиления люминесценции металлическими наночастицами.

Письма в ЖТФ, 2018, том 44, вып. 8 
В настоящей работе впервые экспериментально исследованы особенности люминесценции и ее возбуждения для КТ CdSe/ZnS, нанесенных на поверхность слоя из наночастиц типа ядро/оболочка $\mathrm{Ag} / \mathrm{SiO}_{2}$ с различной толщиной диэлектрической оболочки. Для данной системы продемонстрировано многократное усиление фотолюминесценции квантовых точек при ее возбуждении в спектральной области полосы локализованного поверхностного плазмонного резонанса наночастиц: до 8.7 раз в случае расчетной толщины оболочки $25 \mathrm{~nm}$. Формирование слоя спейсера на индивидуальных металлических наночастицах с последующим образованием слоя частиц и осаждением на него коллоидных квантовых точек обеспечивает управление эффективной толщиной диэлектрической прослойки и подавление нежелательного эффекта туннелирования носителей заряда в металлическую частицу. В результате многократно возрастает интенсивность люминесценции, усиливаемая электромагнитным полем металлических наночастиц.

\section{Список литературы}

[1] Sharma B., Frontiera R., Henry A., Ringe E., Van Duyne R.P. // Mater. Today. 2012. V. 15. N 1-2. P. 16-25.

[2] Jain P.K., Huang X., El-Sayed I.H., El-Sayed M.A. // Plasmonics. 2007. V. 2. N 3. P. 107-118.

[3] Maier S.A., Brongersma H.L., Kik P.G., Meltzer S., Requicha A.A.G., Atwater H.A. // Adv. Mater. 2001. V. 13. N 19. P. 1501-1505.

[4] Catchpole K.R., Polman A. // Opt. Express. 2008. V. 16. N 26. P. 21793-21800.

[5] Tam F., Goodrich G.P., Johnson B.R., Halas N.J. // Nano Lett. 2007. V. 7. N 2. P. 496-501.

[6] Kulakovich O., Strekal N., Yaroshevich A., Maskevich S., Gaponenko S., Nabiev I., Woggon U., Artemyev M. // Nano Lett. 2002. V. 2. N 12. P. 1449 1452.

[7] Munechika K., Chen Y., Tillack A.F., Kulkarni A.P., Plante I.J.L., Munro A.M., Ginger D.S. // Nano Lett. 2010. V. 10. N 7. P. 2598-2603.

[8] Wu J., Lee S., Reddy V.R., Manasreh M.O., Weaver B.D., Yakes M.K., Furrow C.S., Kunets V.P., Benamara M., Salamo G.J. // Mater. Lett. 2011. V. 65. N 23-24. P. 3605-3608.

[9] Кривобок В.С., Николаев С.Н., Новиков А.В., Шалеев М.В., Багаев В.С., Онищенко Е.Е., Лебедев В.С., Скориков М.Л., Уиина Е.В., Кочиев М.В. // Письма в ЖЭТФ. 2016. Т. 104. В. 4. С. 229-234.

Письма в ЖТФ, 2018, том 44, вып. 8 
[10] Лямкина А.А., Мощенко С.П., Дмитриев Д.В., Торопов А.И., Шамирзаев Т.С. // Письма в ЖЭТФ. 2014. Т. 99. В. 4. С. 245-249.

[11] Галяметдинов Ю.Г., Шамилев Р.Р., Нуждин В.И., Валеев В.Ф., Степанов А.Л. // Письма в ЖТФ. 2016. Т. 42. В. 21. С. 15-22.

[12] Li H., Xia H., Wang D., Tao X. // Langmuir. 2013. V. 29. N 16. P. 5074-5079.

[13] Kobayashi Y., Katakami H., Mine E., Nagao D., Konno M., Liz-Marzán L.M. // J. Colloid Interface Sci. 2005. V. 283. N 2. P. 392-396.

[14] Мошников В.А., Таиров Ю.М., Хамова Т.В., Шилова О.А. Золь-гель технология микро- и нанокомпозитов. СПб.: Лань, 2013. 304 с.

[15] Hoonacker V., Englebienne P. // Curr. Nanosci. 2006. V. 2. N 4. P. 359-371.

[16] Mine E., Yamada A., Kobayashi Y., Konno M., Liz-Marzán L.M. // J. Colloid Interface Sci. 2003. V. 264. N 2. P. 385-390.

Письма в ЖТФ, 2018, том 44, вып. 8 